\title{
A questão social na história recente: implicaçôes para a política de saúde no Brasil
}

| ${ }^{1}$ Patrícia Tavares Ribeiro |

Resumo: A “questão social” adquiriu nova relevância no debate acadêmico nos anos 90, em virtude das mudanças observadas nas relações entre Estado, economia e sociedade. Neste debate, o tema da exclusão fundamentou questionamentos à intervenção estatal, particularmente no que se refere à erosão dos sistemas de proteção social. Este artigo, visando a compreender implicações dessas mudanças para a política de saúde no Brasil, sintetiza duas perspectivas distintas da exclusão social, que abordam o problema a partir do desmoronamento da sociedade salarial e de sua repercussão sobre o trabalho; e da desagregação dos princípios de organização da solidariedade e do fracasso da concepção tradicional dos direitos sociais. Conclui que a política de saúde, integrante do sistema de seguridade social brasileiro, se beneficiaria do enriquecimento da noção de direito social; da identificação de meios adequados a uma ação estatal territorializada e compatível com a diferenciação das necessidades sociais; e da análise de medidas inclusivas afetas ao núcleo dos processos de produção e distribuição de riquezas.

> Palavras-chave: políticas públicas, política de saúde, seguridade social, ciências sociais.
'Departamento de Ciências Sociais, Escola Nacional de Saúde Pública, Fundação Oswaldo Cruz. Endereço eletrônico: patriciatr@ensp. fiocruz.br

Recebido em: 19/01/2010. Aprovado em: 23/02/2010. 


\section{A questão social}

A “questão social”, expressão criada no final do séculoXIX, em referência às disfunções da sociedade industrial emergente, foi analisada ao longo do século XX no âmbito do desenvolvimento do Estado Providência no Ocidente. Fundado na utopia de vencer a insegurança social e o medo do futuro instalados pela Revolução Industrial, o Estado Providência foi se estruturando para responder aos riscos e tensões da nova ordem econômica por meio de sistemas sólidos de garantias, resultando no que a literatura jurídica caracteriza como o Estado Social de Direito.

A partir da segunda metade do século XX, entretanto, especificamente no período pós-guerras, o crescimento do desemprego, o surgimento de novas formas de pobreza, a internacionalização da economia, a crise financeira dos Estados nacionais, a fragilização da utopia socialista, o prenúncio da globalização e a ampliação das desigualdades começaram a colocar em xeque os métodos de gestão do social no Estado Providência e sua legitimidade.

Mais recentemente, a realidade e visibilidade do processo de globalização, a mundialização da economia, o ultraliberalismo econômico e a radicalização da competitividade e da concorrência, em suas repercussões sobre o contrato social, as condições de trabalho, os princípios de organização da solidariedade e a concepção tradicional de direitos sociais vêm reproblematizando a questão social (CASTEL, 2000; ROSANVALLON, 1998; FIORI, 1995; BELFIOREWANDERLEY et al., 2000).

A questão social, por dizer respeito aos vínculos históricos que amalgamam cada sociedade e às contradições que podem levar a sua ruptura, "é parte constitutiva dos componentes básicos da organização social - Estado, Nação, cidadania, trabalho, etnia, gênero, entre outros - considerados essenciais para a continuidade e mudança da sociedade" (BELFIORE-WANDERLEY et al., 2000).

Nesta reproblematização, desde os anos 90, a controvertida noção de exclusão social protagoniza debates e seu enfrentamento constitui tema prioritário nas agendas internacionais: torna-se o tema central por excelência, a exigir análises setoriais e políticas públicas que considerem a relação entre a lógica econômica 
e a coesão social. Assim, com destaque para o tema da exclusão, a questão social vem sendo analisada a partir da produção e distribuição de riquezas; da erosão dos sistemas de proteção social, da vulnerabilidade das relações sociais; do questionamento da intervenção estatal; e de mudanças na configuração da sociedade civil e dos movimentos sociais.

A questão social vem se constituindo igualmente objeto da teorização sobre o Estado Democrático de Direito, paradigma constitucional em consolidação no campo do direito, a partir da identificação dos direitos sociais e trabalhistas como direitos fundamentais e da crescente valorização da participação da comunidade na produção e consecução do direito, na institucionalização de uma cidadania plural e aberta à complexidade das relações sociais.

Este trabalho sistematiza algumas ideias de dois sociólogos franceses, cuja produção teórica constitui referência obrigatória para o estudioso que quer aprofundar o tema. Ambos analisam a questão social, porém de perspectivas diferentes: Robert Castel aborda o fenômeno da exclusão/vulnerabilidade social, a partir do deslocamento do trabalho assalariado do centro da sociedade pósindustrial; Pierre Rosanvallon (1998) aborda o problema da exclusão a partir da crise do Estado Providência e da rediscussão dos princípios de organização da solidariedade e da concepção dos direitos sociais.

Com esta sistematização, objetiva-se identificar novos elementos para a análise das especificidades da questão social no Brasil contemporâneo, visando a estudo posterior sobre as oportunidades e medidas que vêm sendo criadas ou adotadas no âmbito das políticas públicas do setor saúde para efetivação do direito universal à saúde e para a redução de desigualdades no país.

\section{O problema da exclusão no contexto de uma sociedade salarial em crise}

Para Robert Castel (2000), a exclusão deve ser analisada tomando como referência o desmoronamento da sociedade salarial e sua repercussão sobre o trabalho suporte privilegiado de inscrição na estrutura social - e sobre o poder integrador do Estado Social.

Em sua perspectiva - voltada, vale lembrar, para a análise da sociedade francesa - a questão social configura-se como crise decorrente da desagregação da sociedade salarial que coloca em causa a função integradora do trabalho, desestabilizando 
a vida social e interrogando a sociedade sobre as situações de vulnerabilidade, precarização e marginalização que vem gerando. Neste contexto, os excluídos são aqueles que se encontram fora dos circuitos das trocas sociais, vivendo situações que representam uma degradação relacionada à posição ocupada anteriormente na ordem do trabalho e das proteções a ela correspondentes. Degradação que, segundo Castel, decorre de processos que se originam no centro e não na periferia da sociedade, e atravessam seu conjunto.

Tal crise, ao atingir parcelas crescentes da população, vem conformando uma massa de "normais inúteis", segundo Donzelot e Estèbe (1994), de "sobrantes", segundo o próprio autor, ou de "inúteis ao mundo", como se falava nas sociedades pré-industriais. Em outros termos, novas populaçôes que sofrem um déficit de integração, populações marginais que se tornaram "inválidas pela conjuntura" recente de transformação das regras do jogo econômico e social. Ressalta o autor, entretanto, que a noção de exclusão encobre uma multiplicidade de "problemas sociais" e não é suficiente para dar conta da diferenciação vivenciada nas situações concretas de infelicidade: desempregados de longa duração, recolhidos à esfera familiar; jovens mal escolarizados à procura de empregos, em andanças sempre recomeçadas, entre outras tantas histórias tristes.

De acordo com a análise da "exclusão" realizada por Castel, a situação positiva de estar integrado, de estar inserido em relações de utilidade social, em relações de interdependência com o conjunto da sociedade, conforme acepção de Durkeim, parece mais difícil de alcançar na atualidade, pois não se refere a pessoas exploradas porém incluídas, mas a "indivíduos que estão completamente atomizados, rejeitados de circuitos que poderiam lhes atribuir uma utilidade social" (CASTEL, 2000, p. 255). Indivíduos que ocupam uma zona intermediária instável entre a área de integração, caracterizada pela associação trabalho estável / inserção relacional sólida, e a exclusão. Esta zona intermediária, de vulnerabilidade social, conjuga a precariedade do trabalho e a fragilidade dos suportes de proximidade, evidenciando relaçóes entre precariedade econômica e instabilidade social.

As medidas que vêm sendo apresentadas para mudar esta conjuntura, relacionadas ao tratamento social do desemprego e à inserção de populações já invalidadas, na lógica da discriminação positiva, podem estar produzindo um deslocamento das intervençôes para as margens do problema, deslocamento típico de uma racionalidade econômica que considera mais fácil e realista intervir sobre os efeitos de uma disfunção social do que controlar os processos que o acionam. 
$\mathrm{O}$ autor destaca, dentre as medidas que foram implementadas na França, a política da cidade, a renda mínima de inserção (RMI), a política de formação para facilitar o acesso ao emprego. Afirma que a observação sociológica mais elementar mostra que a discriminação positiva torna-se facilmente discriminação negativa, dados os limites estreitos entre medidas específicas que visam a ajudar públicos em dificuldades e sua instalação em sistemas de categorização que lhes atribuem um status de cidadãos de segunda classe (CASTEL, 2000, p. 46).

$\mathrm{Na}$ avaliação de Castel (2000), tal tendência se afirma historicamente porque, adotando-se tal perspectiva para as políticas de inserção, a tomada de responsabilidade sobre seus efeitos pode se efetuar sobre um modo técnico, enquanto que o controle de um processo exige um tratamento político. Assim, o autor chama a atenção para a necessidade de se problematizar tais medidas, mesmo reconhecendo que representam um expressivo consenso, em sua relação com as políticas sociais mais gerais.

De acordo com seu argumento, as políticas sociais têm finalidades preventivas e não somente reparadoras, e têm por objetivo sobretudo os fatores de dissociação social, isto é, a gestão dos riscos de dissociação social. Permanecem importantes se considerarmos o aparente enfraquecimento das formas de solidariedades e proximidades e das relações entre pessoas que não passam pelo mercado - terreno fértil para um processo de individualização negativa. As medidas para reinserção social não devem tomar o lugar das proteções sociais garantidas por lei:

se o Estado se retira, há um risco de um quase vazio, da anomia generalizada do mercado, pois este não comporta nenhum dos elementos necessários à coesão social, muito pelo contrário, funciona pela concorrência, "não faz sociedade" (CASTEL, 2000, p. 257).

Para o autor, pensar as condições de inclusão de todos, por meio de um novo pacto de solidariedade, de trabalho e de cidadania é fazer a sociedade hoje. E nesta sociedade o Estado deve assumir seu mandato como fiador de um novo contrato social, como responsável pela realização do pertencimento de todos a uma mesma sociedade (CASTEL, 1998). Assim, o tratamento social do tema da exclusão nas sociedades contemporâneas deve procurar escapar, cuidadosamente, de três armadilhas:

1) a de identificar toda e qualquer disfunção social a processos de exclusão, pois é preciso distingui-los do conjunto dos componentes que constituem hoje a questão social na sua globalidade; 
2) a de negligenciar o modo preventivo de lutar contra a exclusão orientado a intervenções sobre fatores de desregulação da sociedade salarial, no coração dos processos de produção e distribuição de riquezas;

3) a de propor medidas de discriminação positiva que possam se degradar em status de exceção para populações vulneráveis, ao invés de possibilitar sua reintegração ao regime comum.

\section{O problema da exclusão no contexto de um Estado-Providência em crise}

Rosanvallon (1998) identifica, como Robert Castel, que os fenômenos atuais da exclusão não se enquadram nas antigas categorias de exploração do homem, mas diferentemente deste autor, define o que denomina "a nova questão social" como decorrente da inadaptação dos antigos métodos de gestão do social a uma mudança de natureza na crise do Estado-Providência diagnosticada nos anos 70. Tal mudança, verificada nos anos 90, teria introduzido, para além das crises financeira, ideológica e de legitimidade fartamente identificadas na literatura, problemas de natureza filosófica relacionados aos princípios de organização da sociedade e à própria concepção dos direitos sociais.

Segundo Rosanvallon (1998), a nova questão social pode ser pensada a partir de dois problemas principais: a desagregação dos princípios de organização da solidariedade e o fracasso da concepção tradicional dos direitos sociais. No que diz respeito ao primeiro, tal desagregação manifesta-se no sistema de seguro social, mecanismo produtor da solidariedade, baseado na mutualização crescente dos riscos sociais, que identificou o Estado-Providência a uma espécie de sociedade securitária. $\mathrm{O}$ autor argumenta que, na história recente, observa-se a progressiva separação dos dois universos: o do seguro social e o da solidariedade, com um potencial destrutivo desta última.

Fatores como a evolução demográfica; o aumento do desemprego; a individualização do social; a dissociação crescente entre a esfera dos contribuintes e a dos que tem direito a serviços de apoio; o maior conhecimento das diferenças individuais e entre os grupos; a demanda por respostas a situações particulares; o aumento dos descontos sobre os rendimentos para indenizar a exclusão do mercado de trabalho se conjugaram para destruir a visão securitária da solidariedade. Além disso, afirma que as características da atuação do Estado-Providência como 
máquina indenizatória; mecanismo compensatório de disfunções passageiras;

conjunto de intervençôes sobre situações apreendidas como situações de risco conjuntural; promotora da separação entre economia e sociedade tornaram-se insuficientes para gerenciar situações mais estáveis de exclusão.

Nesse contexto, a trajetória institucional da seguridade social de expansão segmentada, sujeição à influência de particularidades corporativas e resistente à lógica mutualista resultou em vasto sistema polimorfo, de fronteiras pouco definidas e de financiamento complexo, reunindo de forma cada vez mais inextricável pagamentos, empréstimos, subvençōes, transferências de todo tipo, comprometendo seu caráter redistributivo (ROSANVALLON, 1998, p. 45).

Quanto ao fracasso da concepção tradicional dos direitos sociais, este é problematizado a partir da inadequação atual da forma pela qual o EstadoProvidência historicamente buscou responder de modo coerente a um amplo leque de problemas sociais. O Estado-Providência teve seu desenvolvimento inscrito no movimento de universalização de direitos e da aplicação ao social do seguro mútuo (mão invisível da solidariedade), sob o pressuposto da igualdade dos indivíduos diante dos diferentes riscos sociais que podiam afetar sua existência (doença, desemprego, aposentadoria, invalidez, etc.).

Esta forma de atuação estaria se esgotando diante de uma sociedade que aparece como um entrelaçamento instável de posições individuais e de múltiplas classificações econômicas, sociais e profissionais, submetida a riscos coletivos de nova escala (catástrofes - naturais, tecnológicas, derivadas de agressões ao meio ambiente) e onde os fenômenos da exclusão e o desemprego de longo prazo definem situaçôes estáveis. Conforme analisa o autor, em situações de desemprego de massa e de aumento da exclusão, onde se multiplicam e se diferenciam situações particulares, a operacionalização dos direitos como compensação de disfunções passageiras e relacionada a riscos conjunturais não funciona (ROSANVALLON, 1998, p. 26).

A superação dessa situação exigiria o enriquecimento da noção de direito social, na direção de um novo direito de inserção, associado ao trabalho e à utilidade social, no contexto de uma configuração nova e aceitável do contrato social, voltada para conciliar a modernização econômica com a reconstrução do tecido social e capaz de personalizar os meios de atuação estatal de forma a contemplar o caráter específico das diferentes situações individuais. 
Esses dois problemas, extremamente sintetizados neste estudo, colocam a necessidade de se ultrapassar velhas oposições entre direitos formais e direitos reais, direitos sociais e políticos; de se reconsiderar as expressões habituais do contrato social; de se reformular a definição do que é justo e equitativo; de se reinventar as formas de solidariedade social; de uma melhor articulação na prática da democracia.

Identificando no momento atual a perda dos alicerces securitários da seguridade social, Rosanvallon (1998) propõe um retorno às origens do EstadoProvidência cívico, no sentido de recolocar questôes relativas ao princípio de justiça que o fundamenta, à definição do social e ao financiamento do sistema de solidariedade social. Afirma que, para ser justo, o Estado não pode limitar-se a distribuir pagamentos e administrar regras gerais. Deve-se tornar um Estadoserviço com a responsabilidade de prover a cada um os meios específicos para mudar o curso da sua vida, superar uma ruptura, antecipar um desarranjo. Um Estado capaz de operacionalizar a equidade não como compensação às desigualdades da natureza ou às disparidades da sorte, mas concedendo permanentemente os meios para permitir ao indivíduo assistido trilhar com segurança os caminhos da existência.

A busca da justiça neste contexto em que a vida política da democracia e a vida social vão se identificar de modo crescente, em que o Estado se torna cada vez mais politizado, deve corresponder a uma arbitragem social e a uma deliberação democrática. Deve consistir na busca de um caminho comum no emaranhado de preferências individuais, escalas de valores, conceitos, que integram a sociedade. Enfim, a busca da justiça deve ser "um esforço de falar uma mesma língua e se pôr de acordo sobre as formas da dívida social” (ROSANVALLON, 1998, p. 64). E assim se estabelecer sobre práticas de argumentação e discussão públicas que substituam a visão estritamente jurídica da igualdade de direitos e levem em conta a diferenciação social a partir de uma abordagem ampliada da equidade.

Em resumo, o autor privilegia na sua análise de alternativas para a reinstituição da solidariedade social e para a redefinição dos direitos, a reinvenção das regras de convivência, a deliberação sobre a justiça e uma nova gestão do social, advogando por um Estado-Providência ativo fundado numa nova cultura política, que reforce o vínculo social, tornando-o mais legível e mais visível. 
Vários elementos do esquema interpretativo desenvolvido na produção científica sistematizada neste trabalho podem ser úteis na análise da questão social brasileira. Muitas das situações analisadas seguramente integram a vida social e política no Brasil, mesmo porque boa parte delas resulta de fenômenos de disseminação global. No Brasil, a exclusão social mostra suas diversas faces, e vale dizer, em proporções e com alguns perfis desastrosos, como nos mostra Zaluar (1997), ao analisar a questão da criminalidade, em sua dimensão social, cultural, institucional e política.

É preciso, entretanto, destacar um aspecto que nos diferencia da sociedade francesa, de onde realizam suas leituras os autores estudados: aos excluídos no Brasil não estão asseguradas garantias públicas contra riscos econômicos decorrentes de disfunções sociais, no âmbito de um sistema sólido de proteção social. A exclusão no Brasil é menos conjuntural: nomeia a situação de pessoas não apenas excluídas da esfera econômica, mas sistematicamente excluídas dos serviços, benesses e garantias oferecidos ou assegurados por nosso precário sistema de proteção social. Esta especificidade complexifica o exame das consequências da degradação da sociedade salarial e das respostas do Estado voltadas à reinclusão.

Inúmeras são as possibilidades de analisar a política de saúde neste contexto e a partir deste referencial. No entanto, uma análise exaustiva das possibilidades que a revisão bibliográfica realizada, extremamente sintetizada no esforço aqui empreendido, permitiria, não seria possível dentro dos limites deste trabalho. Assim, abordaremos apenas a título de uma primeira aproximação, dois campos de análise relacionados à política de saúde, para os quais as produções de Robert Castel e Pierre Rosanvallon podem oferecer importantes linhas de reflexão. O primeiro campo toma como objeto as características da ação do Estado brasileiro na área social e o segundo refere-se ao tema da equidade em saúde.

A literatura que analisa o Estado brasileiro discute se este chegou a se consolidar em algum momento de sua história como um Estado-Providência. A característica mais debatida e aceita entre os estudiosos é de que a trajetória e conteúdo das políticas sociais no país estabeleceram um padrão de cidadania regulada, que assegurou direitos sociais somente aos trabalhadores inseridos no mercado formal de trabalho e seus dependentes. 
Tal característica, reconhecida e criticada social e politicamente durante os anos 80 , legitimou a mudança do modelo de proteção social brasileiro - de um sistema de seguro social, restrito à classe trabalhadora do mercado formal, que se consolidou nos primeiros 70 anos do século passado, para um sistema de seguridade social, orientado por princípios de universalidade e equidade, que estabeleceu um padrão inclusivo para as políticas sociais, a partir da promulgação da Constituição Federal da República Federativa do Brasil, em 1988. O novo modelo articularia solidariamente as áreas da previdência social, saúde e assistência social.

O que se nota, entretanto, é que simultaneamente à implementação do novo modelo no período pós-1988, iniciou-se a separação progressiva dos universos do seguro e da solidariedade, através de uma série de medidas que, desde então, vem descaracterizando a seguridade social brasileira a partir do coração do sistema projetado: seu financiamento. Entre outras medidas desestabilizadoras do arranjo constitucional estabelecido, pode-se destacar, no período 1993/1995, a especialização da fonte contribuição sobre folha de salários para o financiamento exclusivo da Previdência Social (benefícios de aposentadorias e pensões); a desarticulação do Conselho Nacional de Seguridade Social, cuja função era harmonizar as políticas e propostas orçamentárias das três áreas sociais na gestão dos recursos do Orçamento da Seguridade Social (OSS); a criação do Fundo Social de Emergência, transformado posteriormente em Fundo de Estabilização Fiscal, ambos constituídos com parte dos recursos das contribuições sociais que compunham o OSS.

A instabilidade gerada por estes fatos motivou o surgimento, na segunda metade da década de 90, de um amplo movimento político para a elaboração e aprovação de um projeto de Emenda Constitucional que vinculasse parcela dos recursos orçamentários de cada um dos entes federativos para o financiamento das despesas com ações e serviços públicos de saúde, finalmente aprovado em setembro de 2000. Desde então, os diversos atores setoriais vêm discutindo e fazendo acordos quanto a aspectos-chave da operacionalização da Emenda e ao conteúdo da Lei Complementar que regulamentará as inovações por ela introduzidas, até 2008 não aprovada no Congresso Nacional pela difícil conciliação entre os interesses econômicos e sociais envolvidos.

Esta trajetória da seguridade social vem afetando diretamente o processo de institucionalização do Sistema Único de Saúde, particularmente no que diz respeito ao financiamento das inovações necessárias e à implementação da gestão 
descentralizada do sistema, com efeitos negativos na efetivação dos princípios

e diretrizes constitucionalmente estabelecidos (universalização, equidade, integralidade, descentralização), não suficientemente analisados até o momento. Vale lembrar que a possibilidade de concretização de tais princípios e diretrizes na operacionalização do direito à saúde fundamentava-se na solidariedade entre as três áreas - previdência social, saúde e assistência social - no financiamento dos benefícios e serviços oferecidos.

Considerando este percurso acidentado do sistema de proteção social pósConstituição de 1988 e o debate atual sobre o Estado Democrático de Direito, parece pertinente recorrer às reflexôes e sugestôes de Castel e Rosanvallon para melhor qualificar e desenhar alternativas de superação dos principais problemas que limitam a capacidade estatal de atuar de maneira a modificar as situações de extrema infelicidade a que estão submetidas amplas camada da população brasileira. Três caminhos por eles traçados para enfrentar a problemática da nova questão social merecem um cuidadoso exame:

a) o esclarecimento e o enriquecimento da noção de direito social;

b) a identificação de meios mais adequados para uma ação mais justa do Estado, compatível com a diferenciação das necessidades sociais;

c) a análise de medidas relacionadas ao núcleo dos processos de produção e distribuição de riquezas, capazes de gerar inclusão social.

O segundo campo de análise da política de saúde para o qual as reflexōes desses autores apresentam importantes caminhos é aquele referido ao tema da equidade. As desigualdades em saúde, mais bem evidenciadas a partir da institucionalização da gestão descentralizada do Sistema Único de Saúde, vêm sendo recorrentemente tematizadas na agenda política setorial, seja como justificativa para emendas parlamentares, como objetivo prioritário do Conselho Nacional de Saúde no acompanhamento da implementação do SUS; ou como diretriz de destaque na organização da gestão compartilhada do sistema e das intervençôes públicas.

A abordagem a este tema muito se beneficiaria de análises sobre a diferenciação, no território nacional, das situações de privação vivenciadas nas realidades concretas em que vive a população brasileira - que impõe soluções "personalizadas", "territorializadas", para além da administração de regras gerais. Isto implica não somente evitar as armadilhas identificadas por Castel no 
tratamento social da exclusão, quais sejam: de obscurecer situações particulares de pessoas distintas, em lugares distintos; de instituir status de exceção a populações vulneráveis ou de negligenciar determinações econômicas e sociais nucleares; mas, como propõe Rosanvallon, em politizar a questão social e a busca da justiça por meio de processos de participação, articulação e deliberação democrática, de arbitragem social, e de estabelecimento de acordos que reforcem o vínculo social e uma nova cultura política que realize em todos a sensação de pertencimento a uma mesma sociedade.

Os caminhos para alcançar estes objetivos devem ser procurados nas experiências concretas da sociedade brasileira, vivenciadas nos vários recortes do território nacional.

\section{Referências}

BELFIORE-WANDERLEY, M.; BÓGUS, L.; YAZBEK, M.C. (Org.). Apresentação. In: . Desigualdade e a questão social. 2 ed. São Paulo: EDUC, 2000. p. 7-14.

CASTEL, R. As armadilhas da exclusão. In: BELFIORE-WANDERLEY, M.; BÓGUS, L.; YAZBEK, M.C. (Org.). Desigualdade e a questão social. 2 ed. São Paulo: EDUC, 2000. p. 17-50.

CASTEL, R. As metamorfoses da questão social: uma crônica do salário. Petrópolis: Vozes, 1998. 611p.

CASTEL, R. As transformaçōes da questão social. In: BELFIORE-WANDERLEY, M.; BÓGUS, L.; YAZBEK, M.C. (Org.). Desigualdade e a questão social. 2 ed. São Paulo: EDUC, 2000. p. 235-272.

DONZELOT, J; ESTÈBE, P. L'état animateur. Paris: Esprit, 1994. 238p.

FIORI, J.L. Globalização, Estados Nacionais e Políticas Públicas. In: Em busca

do dissenso perdido: ensaios críticos sobre a festejada crise do Estado. Rio de Janeiro: Insight Editorial, 1995. p. 195-214.

ROSANVALLON, P. A nova questão social: repensando o Estado Providência. Brasília: Instituto Teotônio Vilela, 1998. 170 p.

ZALUAR, A. Exclusão e políticas públicas: dilemas teóricos e alternativas políticas. Revista Brasileira de Ciências Sociais, v. 12, n. 35, p. 29-47, 1997. 
Social Issue in recent history: implications for health policy in Brazil

The "social issue" has gained new relevance in the academic debate in the 90 s, owing to the changes observed in relations between state, economy and society. In this debate, the issue of exclusion lies at the base of questions to state intervention, particularly with regard to the erosion of social protection systems. This paper, aiming to understand implications of these changes for health policy in Brazil, summarizes two distinct perspectives of social exclusion, which address the problem from the collapse of wage-based societies, and their impact on work; and, from the breakdown of the principles of solidarity's organization and the failure of the traditional concept of social rights. It concludes that health policy, part of the Brazilian social security system, would benefit from the enrichment of the concept of social right, the identification of appropriate means to a state action territorialized and consistent with the differentiation of social needs, and the analysis of inclusive interventions related to the core of the production and distribution of wealth systems.

Key words: public policies, health policy, social welfare, social sciences. 